\title{
The Influence of CAR, LDR and BOPO on ROA at Conventional State- Owned Banks Listed on the Indonesia Stock Exchange
}

\section{Pengaruh CAR, LDR Dan BOPO Terhadap ROA Pada Bank Bumn Konvesional Yang Terdaftar Di Bursa Efek Indonesia}

\author{
Ferona Gustiana 1); Ahmad Soleh2); Zahra Indah Ferina ${ }^{2)}$ \\ 1)Study Program of Accounting, Faculty of Economic, Universitas Dehasen Bengkulu \\ ${ }^{2)}$ Department of Management, Faculty of Economic, Universitas Dehasen Bengkulu \\ Email: ${ }^{1)}$ veronagustiana18@gmail.com; ${ }^{2)}$ ahmadsolehse81@yahoo.co.id
}

How to Cite:

Gustiana, F., Soleh, A., Ferina, Z. I. (2021). The Influence of CAR, LDR and BOPO on ROA at Conventional StateOwned Banks Listed on the Indonesia Stock Exchange. EMAK: Jurnal Ekonomi Manajemen Akuntansi Dan Keuangan, 2(4). DOI: https://doi.org/10.53697/emak.v2i4

ARTICLE HISTORY

Received [12 Agust 2021]

Revised [25 Agust 2021]

Accepted [05 October 2021]

KEYWORDS

CAR, LDR, BOPO, ROA

This is an open access article under the $C C-B Y$-SA license

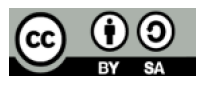

\section{ABSTRAK}

Penelitian ini bertujuan untuk dilakukannya pengukuran kondisi suatu entitas adalah untuk mempertahankan kelangsungan hidup perusahaan dalam jangka panjang, karena profitabilitas yang dilihat dari ROA menunjukkan apakah perusahaan perbankan tersebut mempunyai prospek yang baik kedepannya. Tujuan penelitian ini adalah mengetahui pengaruh CAR, LDR dan BOPO Terhadap ROA Pada Bank BUMN Konvensional yang terdaftar di Bursa Efek Indonesia. Sampel dalam penelitian ini adalah empat bank konvesional di Indonesia yaitu BNI, BRI, BTN dan Bank Mandiri. Penelitian dilakukan dari tahun 2010 sampai 2019. Metode pengumpulan data menggunakan metode dokumentasi Analisis data yang digunakan adalah regresi linier berganda, koefesien determinasi dan uji hipotesis. Dari perhitungan persamaan regresi linier berganda dapat diketahui bahwa pengaruh CAR, LDR dan BOPO Terhadap ROA Pada Bank BUMN Konvensional menghasilkan hasil uji regresi : $Y=11,602+0,015 X 1+$ 0,005 X2 - 0,108 X3 .Koefesien determinasi yang diperoleh $\mathrm{R}$ square sebesar 0,785. Hal ini berarti bahwa X1 (CAR), X2 (LDR) dan X3 (BOPO ) berpengaruh terhadap ROA (Y) sebesar 78,5\% sedangkan sisanya (100 $\%-78,5 \%=21,5 \%$ ) dipengaruhi oleh variabel-variabel lainnya yang tidak diteliti dalam penelitian ini. Hasil pengujian uji t, menunjukan adanya pengaruh yang signfikan secara terpisah antara CAR, LDR dan BOPO Terhadap ROA Pada Bank BUMN Konvensional. Hasil pengujian uji $F$ menunjukkan nilai signifikansi sebesar 0,000 , karena nilai signifikan lebih kecil dari 0,05 maka artinya CAR, LDR dan BOPO memilik pengaruh yang signfikan secara bersama-sama terhadap ROA Pada Bank BUMN Konvensional.

\section{ABSTRACT}

The purpose of this study was to determine the effect of CAR, LDR and $B O P O$ on ROA at conventional state-owned banks listed on the Indonesia Stock Exchange. The sample in this study were four conventional banks in Indonesia, namely BNI, BRI, BTN and Bank Mandiri. The study was conducted from 2010 to 2019. The data collection method used the documentation method. Data analysis used was multiple linear regression, coefficientof determination and hypothesis testing. From the calculation of the multiple linear regression equation, it can be seen that the effect of $C A R, L D R$ and OEOI on ROAat conventional state-owned banks results in 
regression test results: $Y=11.602+0.01 X 1+0.005 X 2-0.108 X 3$. The coefficient of determination obtained by $R$ square is 0.785 . This means that $X 1(C A R), X 2(L D R)$ and $X 3(B O P O)$ have an effect on ROA $(Y)$ by $78.5 \%$ while the rest $(100 \%-78.5 \%=21.5 \%)$ are influenced by variables. others who were not examined in this study. The test results show that there is a significant effect separately between CAR, LDR and BOPO on ROA at conventional state-owned banks. The results of the $F$ test show a significance value of 0.000 , because the significant value is less than 0.05 , it means that CAR, LDR and BOPO have a significant effect together on ROA at conventional state-owned banks.

\section{PENDAHULUAN}

Bank merupakan perusahaan yang bergerak dalam bidang keuangan, artinya aktivitas perbankan selalu berkaitan dalam bidang keuangan. Aktivitas perbankan yang pertama adalah menghimpun dana dari masyarakat luas yang dikenal dengan istilah di dunia perbankan adalah kegiatan funding (Kasmir, 2015: 26). Bank juga memberikan pelayanan dalam lalu lintas sistem pembayaran sehingga kegiatan ekonomi masyarakat dapat berjalan dengan lancar. Dengan sistem pembayaran yang efisien, aman dan lancar maka perekonomian dapat berjalan dengan baik. Karena manfaatnya yang begitu penting bagi perekonomian, maka setiap Negara berupaya agar perbankan selalu berada dalam kondisi yang sehat, aman dan stabil.

CAR sebagai variabel yang mempengaruhi profitabilitas didasarkan hubungannya dengan tingkat resiko bank. CAR yang ditetapkan oleh Bank 3 Indonesia ini, mengacu pada ketentuan atau standar internasional yang dikeluarkan oleh Banking for International Settlement (BIS). Dengan meningkatnya modal sendiri maka kesehatan bank yang terkait dengan rasio permodalan (CAR) semakin meningkat. Dengan adanya modal yang cukup memungkinkan suatu bank dalam melaksanakan aktivitasnya tidak mengalami kesulitan dan kerugian yang mungkin akan timbul kemudian berdampak pada menaiknya tingkat profitabilitas (Fahmi, 2016:112).

Negeri (inkaso) dan jasa lainya. Untuk mengukur kemampuan bank memperoleh keuntungan dapat digunakan berbagai ukuran antara lain Return On Asset (ROA) ROA merupakan perbandingan antara laba (sebelum pajak) dengan total asset bank, rasio ini menunjukan tingkat efisiensi pengelolaan asset yang dilakukan oleh bank yang bersangkutan. Bank Indonesia juga lebih mengutamakan nilai profitabilitas suatu bank yang diukur dengan ROA. Semakin besar ROA menunjukan kinerja perusahaan semakin baik, karena tingkat kembalian (return) semakin besar (Kasmir, 2015:88). Alasan untuk dilakukannya pengukuran kondisi suatu entitas adalah untuk mempertahankan kelangsungan hidup perusahaan dalam jangka panjang, karena profitabilitas yang dilihat dari ROA menunjukkan apakah perusahaan perbankan tersebut mempunyai prospek yang baik kedepannya. Dengan demikian setiap bank akan selalu berusaha meningkatkan profitabilitasnya, dimana semakin tinggi profitabilitas suatu bank maka kinerja bank tersebut dapat dikatakan baik, karena telah beroperasi secara efektif dan efesien. Sementara rasio permodalan yang lazim digunakan unutuk mengukur kesehatan bank adalah Capital Adequacy Ratio (CAR). Penetapan

\section{LANDASAN TEORI}

Bank BUMN Konvensional secara berkesinambungan terus melakukan evaluasi dan perbaikan terutama di bidang pelayanan, pengembangan produk, fungsi pemasaran serta pengembangan jaringan kantor, agar mampu mewujudkan visi menjadi bank yang terpercaya dalam pelayanan jasa keuangan serta mampu menunjang pembangunan daerah. Mengingat fungsi, posisi dan peranan Bank BUMN Konvensional yang terdaftar di Bursa Efek Indonesia di tengah-tengah masyarakat yang strategis, maka kepentingan untuk mengukur kemampuan bank dalam menjalankan operasionalnya menjadi begitu penting agar dikemudian hari Bank BUMN 
p-ISSN 2798-0499 e-ISSN 2798-0502

Konvensional yang terdaftar di Bursa Efek Indonesia lebih dapat diterima oleh masyarakat dan tetap di percaya oleh kalangan pemerintah maupun swasta dalam pengelolaan keuangan bisnisnya. Bank BUMN Konvensional yang terdaftar di Bursa Efek Indonesia memiliki komitmen tinggi untuk secara konsisten menjalankan fungsi intermediasinya dalam mendukung perekonomian Indonesia. Berdasarkan latar belakang di atas maka judul penelitian ini adalah "Pengaruh CAR, LDR dan BOPO Terhadap ROA Pada Bank BUMN Konvensional Yang Terdaftar di Bursa Efek Indonesia".

Agar dapat melaksanakan fungsi sebagai penghimpun dan penyalur dana masyarakat dengan baik, bank harus dipercaya oleh masyarakat. Karena sebagian dana yang digunakan oleh perbankan dalam melakukan penyaluran dana adalah dana nasabah atau masyarakat yang dihimpun melalui simpanan, sedangkan modal sendiri bank sangat relative sedikit, maka dikatakan bank sebagai lembaga kerpercayaan (Sulhan dan Ely, 2016: 4). Sebagai perantara keuangan bank akan memperoleh keuntungan dari selisih bunga yang diberikan kepada penyimpan (bunga simpanan) dengan bunga yang diterima dari peminjam (bunga kredit). Bank juga memberikan jasajasa seperti2 pengiriman uang (transfer), penagihan surat-surat berharga yang berasal dari dalam kota, penagihan surat-surat berharga yang berasal dari luar kota.

\section{Bank BNI}

PT. Bank Negara Indonesia (Persero) Tbk adalah sebuah bank pemerintah di Indonesia. BNI dipimpin oleh seorang Direktur Utama yang saat ini dijabat oleh Gatot M. Suwondo. BNI adalah bank komersial tertua dalam sejarah Republik Indonesia. Bank ini didirikan pada tanggal 5 Juli tahun 1946. Saat ini BNI mempunyai 914 kantor cabang di Indonesia dan 5 di luar negeri. BNI juga mempunyai unit perbankan syariah. Didirikan tahun 1946 dan dipersiapkan menjadi Bank Sirkulasi atau Bank Sentral yang bertanggung jawab menerbitkan dan mengelola mata uang RI. Beberapa bulan setelah pendiriannya, Bank Negara Indonesia mulai mengedarkan alat pembayaran resmi pertama Oeang Republik Indonesia atau ORI.

\section{Bank BRI}

Bank Rakyat Indonesia (BRI) adalah salah satu bank milik pemerintah yang terbesar di Indonesia. Pada awalnya Bank Rakyat Indonesia (BRI) didirikan di Purwokerto, Jawa Tengah oleh Raden Bei Aria Wirjaatmadja dengan nama De Poerwokertosche Hulp en Spaarbank der Inlandsche Hoofden atau "Bank Bantuan dan Simpanan Milik Kaum Priyayi Purwokerto", suatu lembaga keuangan yang melayani orang orang berkebangsaan Indonesia (pribumi). Lembaga tersebut berdiri tanggal 16 Desember 1895, yang kemudian dijadikan sebagai hari kelahiran BRI

\section{Bank BTN}

Bank Tabungan Negara atau BTN adalah Badan Usaha Milik Negara Indonesia yang berbentuk perseroan terbatas dan bergerak di bidang jasa keuangan perbankan. Sejak tahun 2000, bank ini dipimpin oleh Iqbal Latanro sebagai direktur utama.

\section{Bank Mandiri}

Bank Mandiri berdiri pada tanggal 2 Oktober 1998 sebagai bagian dari program restrukturisasi perbankan yang dilaksanakan oleh pemerintah Indonesia. Pada bulan Juli 1999, empat bank milik pemerintah yaitu, Bank Bumi Daya, Bank Dagang Negara, Bank Ekspor Impor Indonesia dan Bank Pembangunan Indonesia, bergabung menjadi Bank Mandiri. Sejarah keempat Bank tersebut dapat ditelusuri lebih dari 140 tahun yang lalu. Keempat Bank tersebut telah turut membentuk riwayat perkembangan dunia perbankan di Indonesia. Hasil penelitian ini menunjukkan bahwa jika BOPO meningkat maka laba semakin menurun. Tingkat efisiensi bank dalam menjalankan operasinya berpengaruh terhadap tingkat pendapatan atau earning yang dihasilkan oleh bank. Jika kegiatan operasional dilakukan dengan efisien (dalam hal ini nilai rasio BOPO rendah) maka laba yang dihasilkan bank tersebut akan naik. Selain itu, besarnya rasio BOPO juga disebabkan karena tingginya biaya dana yang dihimpun dan rendahnya pendapatan bunga dari 
penanaman dana. Semakin besar BOPO, maka akan semakin kecil atau menurun kinerja keuangan perbankan, begitu juga sebaliknya,jika BOPO semakin kecil maka dapat disimpulkan bahwa kinerja keuangan perbankan semakin meningkat atau membaik. Hasil temuan ini mendukung hasil penelitian dari Dewi (2014)yang menunjukkan bahwa BOPO berpengaruh negatif dan signifikan terhadap ROA

\section{METODE PENELITIAN}

\section{Regresi Linear Berganda}

Metode analisis untuk mengetahui variabel independen yang mempengaruhi secara signifikan terhadap ROA pada perusahaan pada Bank BUMN Konvensional yang terdaftar di Bursa Efek Indonesia Periode 2010-2019 yaitu CAR, LDR dan BOPO digunakan persamaan umum regresi linier berganda atas dua variabel bebas terhadap variabel tidak bebas umum regresi berganda. Rumus umum dari regresi linier berganda menurut Umar (2013:126)

yaitu :27

$$
Y=a+B 1 X 1+B 2 X 2+B 3 X 3+e
$$

Dimana :

$$
\begin{array}{ll}
\mathrm{Y} & =\mathrm{ROA} \text { (Return on Asset) } \\
\mathrm{a} & =\text { Konstanta } \\
\mathrm{B} 1,2,3 & =\text { Penaksiran koefisien regresi } \\
\mathrm{X} 1 & =\text { CAR (Capital Adequacy Ratio) } \\
\mathrm{X} 2 & =\text { LDR (Loan } \text { Deposit Ratio) } \\
\mathrm{X} 3 & =\text { BOPO (Biaya Operasinal terhadap Pendapatan Operasional } \\
\mathrm{e} & =\text { Variabel Residual (tingkat kesalahan) }
\end{array}
$$

\section{Koefisien Determinasi (R2)}

Kekuatan pengaruh variabel bebas terhadap variasi variabel terikat dapat diketahui dari besarnya nilai koefisien determinasi (R2 ) yang berada antara nol dan satu. Nilai yang mendekati satu berarti variabel-variabel independen memberikan hampir semua inforrmasi yang dibutuhkan untuk memprediksi variasi variabel dependen (Ghozali, 2015:82). Interpretasi: Jika R2 mendekati 1 (semakin besar nilai R2 ), menunjukkan bahwa sumbangan atau kontribusi variabel bebas terhadap variabel terikat secara simultan semakin kuat.; dan Jika R2 mendekati 0 (semakin kecil nilai R2 ), menunjukkan bahwa sumbangan atau kontribusi variabel bebas terhadap variabel terikat secara simultan semakin lemah.

\section{HASIL DAN PEMBAHASAN}

\section{Pengaruh CAR Terhadap ROA}

Hipotesis pertama yang diajukan menyatakan bahwa Capital Adequacy Ratio (CAR) berpengaruh positif terhadap Return on Assets (ROA). Dari hasil penelitian diperoleh koefisien regresi untuk variabel Capital Adequacy Ratio (CAR) pada bank BUMN Konvensonal sebesar 0,015 dengan nilai signifikansi sebesar 0,004 , dimana nilai ini signifikan pada tingkat signifikansi 0,05 karena lebih kecil daripada 0,05. Dengan demikian hipotesis pertama yang menyatakan CAR berpengaruh positif terhadap ROA dapat diterima. Hasil penelitian ini menunjukkan bahwa jika CAR meningkat maka laba juga semakin meningkat sehingga ROA semakin meningkat. CAR yang semakin rendah menyebabkan turunnya kepercayaan masyarakat. Hal ini disebabkan karena salah satu fungsi 45 modal adalah untuk menjaga kepercayaan masyarakat (Sinungan, 2015:98).

Modal bank digunakan untuk menjaga kepercayaan masyarakat, khususnya masyarakat peminjam. Kepercayaan masyarakat dapat terlihat dari besarnya dana pihak ketiga yang harus melebihi jumlah setoran modal dari pemegang saham. Kepercayaan masyarakat amat penting 
p-ISSN 2798-0499 e-ISSN 2798-0502

artinya bagi bank karena dengan demikian bank akan dapat menghimpun dana untuk keperluan operasional. Ini berarti modal dasar bank akan bisa digunakan untuk menjaga posisi likuiditas dan investasi dalam asset tetap. Sebaliknya semakin tinggi CAR yang dicapai oleh suatu bank menunjukkan kinerja bank semakin baik karena bank tersebut mampu untuk menutupi penurunan aktivanya sebagai akibat dari kerugiankerugian bank yang disebabkan oleh aktiva yang berisiko dengan kecukupan modal yang dimilikinya. Dengan kata lain, semakin kecil risiko suatu bank maka semakin meningkat keuntungan yang diperoleh (Kuncoro, 2015:101). Hasil temuan ini mendukung hasil penelitian dari Aidah (2014) yang menunjukkan bahwa CAR berpengaruh positif dan signifikan terhadap ROA .

\section{Pengaruh LDR Terhadap ROA}

Loan to Deposit Ratio (LDR) berpengaruh positif terhadap Return on Assets (ROA). Dari hasil penelitian diperoleh koefisien regresi variabel LDR dengan arah positif sebesar 0,005 dan nilai signifikansi 46 sebesar 0,018, dimana nilai signifikan lebih kecil daripada 0,05. Dengan demikian hipotesis kedua yang menyatakan LDR berpengaruh positif terhadap ROA dapat diterima. Hasil penelitian ini menunjukkan bahwa semakin tinnggi LDR menunjukkan meningkatnya bank dalam menyalurkan kredit.

LDR yang tinggi menunjukkan bank sepenuhnya mampu mengoptimalkan penggunaan dana masyarakat untuk melakukan ekspansi kredit. LDR yang berada di bawah target dan limitnya, maka akan dikatakan bahwa bank memelihara alat likuid yang berlebihan dan ini akan menimbulkan tekanan terhadap pendapatan bank berupa tingginya biaya pemeliharaan kas yang menganggur (Kuncoro, 2015:109). Sehingga dapat dikatakan bahwa bank tersebut tidak menjalankan fungsinya sebagai intermediasi dengan baik. Semakin tinggi LDR maka laba yang diperoleh oleh bank tersebut akan meningkat (dengan asumsi bahwa bank tersebut mampu menyalurkan kreditnya dengan efektif sehingga diharapkan jumlah kredit macetnya rendah). Hasil temuan ini mendukung hasil penelitian dari Alidah (2014) yang menunjukkan bahwa LDR berpengaruh positif dan signifikan terhadap ROA

\section{Pengaruh BOPO Terhadap ROA}

Hipotesis ketiga yang diajukan menyatakan bahwa Biaya Operasi Terhadap Pendapatan Operasi (BOPO) berpengaruh negatif terhadap 47 Return on Assets (ROA). Dari hasil penelitian diperoleh koefisien regresi variabel BOPO dengan arah negatif sebesar -0,108 dengan nilai signifikansi sebesar 0,000, dimana nilai signifikan lebih kecil daripada 0,05. Dengan demikian hipotesis ketiga yang menyatakan BOPO berpengaruh terhadap ROA dapat diterima. Hasil penelitian ini menunjukkan bahwa jika BOPO meningkat maka laba semakin menurun. Tingkat efisiensi bank dalam menjalankan operasinya berpengaruh terhadap tingkat pendapatan atau earning yang dihasilkan oleh bank. Jika kegiatan operasional dilakukan dengan efisien (dalam hal ini nilai rasio BOPO rendah) maka laba yang dihasilkan bank tersebut akan naik. Selain itu, besarnya rasio BOPO juga disebabkan karena tingginya biaya dana yang dihimpun dan rendahnya pendapatan bunga dari penanaman dana. Semakin besar BOPO, maka akan semakin kecil atau menurun kinerja keuangan perbankan, begitu juga sebaliknya, jika BOPO semakin kecil maka dapat disimpulkan bahwa kinerja keuangan perbankan semakin meningkat atau membaik. Hasil temuan ini mendukung hasil penelitian dari Dewi (2014) yang menunjukkan bahwa BOPO berpengaruh negatif dan signifikan terhadap ROA.

\section{KESIMPULAN DAN SARAN}

1. Dari perhitungan persamaan regresi linier berganda dapat diketahui bahwa pengaruh CAR, LDR dan BOPO Terhadap ROA Pada Bank BUMN Konvensional menghasilkan hasil uji regresi : $Y=11,602+0,015 \times 1+0,005 \times 2-0,108 \times 3$ 
2. Koefesien determinasi yang diperoleh $R$ square sebesar 0,785 . Hal ini berarti bahwa $X 1$ (CAR), X2 (LDR) dan X3 (BOPO) berpengaruh terhadap ROA (Y) sebesar 78,5\% sedangkan sisanya $(100 \%-78,5 \%=21,5 \%)$ dipengaruhi oleh variabel-variabel lainnya yang tidak diteliti dalam penelitian ini.

3. Hasil pengujian uji t, menunjukan adanya pengaruh yang signfikan secara terpisah antara CAR, LDR dan BOPO Terhadap ROA Pada Bank BUMN Konvensional

4. Hasil pengujian uji $F$ menunjukkan nilai signifikansi sebesar 0,000 , karena nilai signifikan lebih kecil dari 0,05 maka artinya CAR, LDR dan BOPO memilik pengaruh yang signfikan secara bersama-sama terhadap ROA Pada Bank BUMN Konvensional.

\section{DAFTAR PUSTAKA}

Alidah. Yonira Bagiani. 2014. Pengaruh CAR, NPL, BOPO, Dan LDR Terhadap Profitabilitas Bank (Roa) Pada Bank BUMN Konvensional Yang Terdaftar Di Bursa Efek Indonesia Periode 2014-2012. Skripsi. Program Studi Manajemen-Jurusan Manajemen Fakultas Ekonomi Universitas Negeri Yogyakarta

Astuti Dewi, 2017, Manajemen Keuangan Perusahaan, cetakan pertama, Penerbit : Ghalia Indonesia, Jakarta

Bank Indonesia, Surat Edaran Nomor 6/23/DPNP tanggal 31 Mei 2004. perihal Tatacara Penilaian Kesehatan Bank Umum.

Dendawijaya, Lukman. 2015. Manajemen Perbankan. Bogor: Ghalia Indonesia.

Dewi, Kadek Ayu Krisna. 2014. Pengaruh Capital Adequacy Ratio (CAR), Loan To Deposit Ratio (LDR), Dan Perbandingan Biaya Operasional Dengan Pendapatan Operasional (BOPO) Terhadap Return On Assets (ROA) Pada Bank Umum Yang Terdaftar Di Bursa Efek Indonesia Tahun 2015-2012. Jurusan Akuntansi Program S1 Ak Universitas Pendidikan Ganesha Volume 2 No.1

Fahmi, Irham , 2016, Analisis Kinerja Keuangan, Bandung : Alfabeta

Ghozali, Imam, 2015. Aplikasi Analisis Multivariate dengan Program SPSS. Yogyakarta: Badan Penerbit BPFE.

Hanafi, Mamduh dan Halim, Abdul. 2013. Analisis Laporan Keuangan. Edisi Ketiga. Cetakan Pertama. Penerbit UPP Sekolah Tinggi IImu Manajemen YKPN. Yogyakarta

Harmono, 2014, Manajemen Keuangan Berbasis Balanced Scorecard (Pendekatan Teori, Kasus, dan Riset Bisnis), Bumi Aksara, Jakarta.

Husnan Suad dan Pudjiastuti Enny, 2014, Dasar-Dasar Manajemen Keuangan, edisi pertama, cetakan pertama, edisi pertama, cetakan pertama, Penerbit : UPP AMP YKPN, Yogyakarta

Kasmir, 2015, Analisis Laporan Keuangan, Jakarta: PT. Rajagrafindo Persada

Kuncoro dan Suhardjono, 2016, Manajemen Perbankan (Teori dan Aplikasi), Edisi Pertama, Penerbit BPFE, Yogyakarta

Martono dan Harjito Agus, 2015, Manejemen Keuangan, edisi pertama, cetakan pertama, Penerbit : Ekonisia Kampus Fakultas Ekonomi UII, Yogyakarta

Martono, 2014, Bank dan Lembaga Keuangan Lainnya, Yogyakarta: Ekonisia Kampus Fakultas Ekonomi UII

Muchlis. 2014. Analisis Laporan Keuangan, Yogyakarta : Gramedia.

Munawir, 2014, Analisa Laporan Keuangan. Liberty, Yogyakarta

Riyadi, Universitas Indonesia

Sugiyono, 2017, Metode Penelitian Kuantitatif Kualitatif dan R\&D, Bandung :

Alfabeta

Sulhan dan Ely Siswanto. 2016. Manajemen Bank Konvensional dan Syariah. Malang : UIN Malang Press

Supriyadi, Edy, 2014, SPSS + Amos, Jakarta : In Media

Sutrisno, 2018, Manajemen Keuangan, Teori, Konsep dan Aplikasi, edisi pertama, cetakan ketiga, Penerbit : Ekonesia, Yogyakarta.

Umar. Husein, 2013. Metode Penelitian Untuk Skripsi dan Tesis Bisnis. Jakarta. PT Rajagrafindo Persada 
p-ISSN 2798-0499 e-ISSN 2798-0502

Wild, John J dkk. 2015. Analisis Laporan Keuangan. Edisi kedelapan buku 1. Salemba Empat. Jakarta. Yaya Rizal, 2014. Akuntansi Perbankan Syariah Teori dan Praktik Kontemporer. Jakarta: Salemba Empat.

338 | Ferona Gustiana, Ahmad Soleh, Zahra Indah Ferina; The Influence of CAR... 